\title{
Rancang Bangun Alat Uji Tarik Serat Alam
}

\author{
Muhammad Arsyad $^{1 *}$, Jeremiah Ritton ${ }^{2}$, Abdul Rachman ${ }^{3}$, Dewi Rachma Ayu Lestari ${ }^{4}$, Edyson \\ Palembangan 5 \\ 1,2,3,4,5 Jurusan Teknik Mesin, Politeknik Negeri Ujung Pandang, Makassar 90245, Indonesia \\ email_arsyadhabe@poliupg.ac.id
}

\begin{abstract}
The aim of this research are to design and to make natural fiber tensile strength test as well as to recognize the characteristics of natural fiber. The specimen testing is done using ASTM 3379-02 standard. The methods that we used are designing, making, assembling and testing. This equipment is designed simply by using water as a load. When used, the water continues to be flowed to the reservoir which is connected in such a way that the fiber breaks. When the fiber breaks, the mass of water is weighed as a burden which causes the fiber to break. Tensile strength of the results of testing equipment is $282.35 \mathrm{~N} / \mathrm{mm}^{2}$ compared with the tensile strength of the results of the tensile test equipment at UNM $186.42 \mathrm{~N} / \mathrm{mm}^{2}$ and the value of the tensile strength of the literature $284.08 \mathrm{~N} / \mathrm{mm}^{2}$. The value obtained is between the tensile strength of the results of the UNM tensile test equipment with the tensile strength of the literature. According to these results it was concluded that the tensile test equipment made can be used to determine the tensile strength of natural fibers, one of which is coconut fiber. The natural fiber tensile test equipment can be used to determine the tensile strains of coconut fiber.
\end{abstract}

Key words : coconut fiber; tensile; strength, equipment.

\begin{abstract}
Abstrak: Tujuan penelitian ini ialah untuk merancang dan membuat alat uji tarik serat alam serta untuk mengenali karakteristik serat alami. Pengujian spesimen dilakukan dengan menggunakan standar ASTM 3379-02. Metode yang digunakan yaitu merancang, membuat, merakit, dan menguji. Alat ini dirancang secara sederhana dengan menggunakan air sebagai media beban. Pada saat digunakan, air terus dialirkan ke penampungan yang dihubungan sedemikian rupa dengan serat hingga serat meregang akhirnya putus. Pada saat serat putus, massa air ditimbang sebagai beban yang menyebabkan serat putus. Kekuatan tarik hasil pengujian alat yang dibuat 282,35 $\mathrm{N} / \mathrm{mm}^{2}$ dibandingan dengan kekuatan tarik hasil uji tarik alat di UNM 186,42 N/mm dan nilai kekuatan tarik literatur $284,08 \mathrm{~N} / \mathrm{mm}^{2}$. Nilai yang diperoleh yaitu antara kekuatan tarik hasil uji alat uji tarik UNM dengan kekuatan tarik literatur. Sesuai hasil tersebut disimpulkan bahwa alat uji tarik yang dibuat dapat digunakan untuk mengetahui kekuatan tarik serat alam salah satunya serat sabut kelapa. Alat uji tarik serat alam tersebut dapat digunakan untuk menentukan regangan tarik serat kelapa.
\end{abstract}

Kata kunci : serat sabut kelapa; tarik; kekuatan, peralatan.

\section{PENDAHULUAN}

Serat banyak dimanfaatkan di dunia perindustrian, seperti pabrik pembuat tali, industri tekstil, industri kertas. Karena mempunyai kekuatan yang tinggi, serat sangat baik untuk material komposit. Perkembangan komposit tidak hanya komposit sintesis saja tetapi juga mengarah kekomposit berpenguat serat alam. Hal disebabkan keistimewaan sifatnya yang dapat didaur ulang atau terbarukan, sehingga mengurangi konsumsi petrokimia maupun gangguan lingkungan hidup. Komposit serat alam memilki keunggulan lain bila dibandingkan dengan serat gelas. Komposit serat alam sekarang banyak digunakan karena jumlahnya banyak, lebih ramah lingkungan karena mampu terdegradasi secara alami, harganyapun lebih murah dibandingkan seratgelas. Pemanfaatan serat alam (natural fibers) seperti serat ijuk, kenaf, serat sabut kelapa, serat bambu, abaca, rosella, serat nanas, serat jerami, serat pisang, danserat alam yang lain yang biasa dimanfaatkan sebagai material temuan yang bersifat inovatif [1].

Dalam pembuatan komposit serat alam diperlukan material dengan spesifikasi dan sifat-sifat yang khusus pada setiap bagiannya. Salah satu sifat terpenting dari serat alam adalah sifat mekanik. Sifat mekanik terdiri dari keuletan, kekerasan, kekuatan, dan ketangguhan. Sifat mekanik merupakan salah 
satu acuan untuk melakukan proses selanjutnya terhadap suatu material. Untuk mengetahui sifat mekanik suatu material harus dilakukan pengujian terhadap material tersebut. Salah satu pengujian yang dilakukan untuk mengetahui sifat mekanik dari material tersebut adalah pengujian tarik [2]. Uji tarik adalah suatu metode yang digunakan untuk menguji kekuatan suatu bahan/material dengan cara memberikan beban gaya yang sesumbu. Pengujian tarik digunakan untuk mengukur ketahanan suatu material terhadap gaya statis yang diberikan secara lambat. Untuk mengukur ketahanan material tersebut dibutuhkan sebuah alatuji yang mampu untuk mengukur gaya dan perpanjangan dari material tersebut. Alat uji tarik dapat dikelompokkan menjadi dua, yaitu untuk logam dan non logam. Sedangkan pembagian jenis alat uji tarik dibagi menjadi tiga, yaitu komputerisasi/digital, konvensional dan manual. Ketersediaan alat uji tarik khususnya di Makassar baik untuk logam maupun non logam sangatlah terbatas sehingga dapat menghambat kelancaran penelitian tentang kekuatan serat alam sebagai bahan penguat komposit.

Uji tarik adalah suatu metode yang digunakan untuk menguji kekuatan suatu bahan/material dengan cara memberikan beban gaya yang sesumbu. Hasil yang didapatkan dari pengujian tarik sangat penting untuk rekayasa teknik dan desain produk karena menghasilkan data kekuatan material. Pengujian uji tarik ini digunakan untuk mengukur ketahanan suatu material terhadap gaya statis yang diberikan secara lambat. Kekuatan suatu komponen selalu menjadi pertimbangan dalam penggunaannya. Maka kekuatan dan kekakuan material komposit sangat ditentukan oleh serat penguat (fiber), resin sebagai pengikat dan katalis sebagai unsur lain [3]. Kekuatan suatu komponen selalu menjadi pertimbangan dalam penggunaannya. Maka kekuatan dan kekakuan material komposit sangat ditentukan oleh serat penguat (fiber), resin sebagai pengikat dan katalis sebagai unsur lain. Pengujian kekuatan bahan yang dilakukan merupakan perbandingan antara gaya yang diperlukan untuk menarik spesimen uji dengan pergerakan atau pertambahan panjang (elongasi) yang terjadi dari spesimen uji [3].

\section{METODE PENELITIAN}

Pembuatan alat uji tarik serat alam ini dibagi beberapa tahap yaitu perancangan, pembuatan, dan pengujian.

\section{A. Perancangan}

Bahan-bahan yang digunakan dalam pembuatan alat uji tarik tersebut meliputi: besi ST 42, kayu, lem, keran air, tali baja, pipa stainles, fiber, ragum, selang plastik, pewarna, roda, karton, serat sabut kelapa. Bahan-bahan tersebut tersedia di toko bahan bangunan di kota Makassar. Sedangkan alat-alat yang digunakan seperti: mikroskop digital, timbangan digital, mesin bubut, mesin bor, gergaji, mesin las, gunting, cat dan kelengkapannya.

\section{B. Pembuatan}

Komponen-komponen alat uji tarik serat ini terdiri dari:
a. Meja kayu
b. Tiang/Poros
c. Meja pelat
d. Alat bantu ragum atas
e. Alat bantu ragum bawah
f. Ragum
g. Katrol
h. Kaki/Roda
i. Wadah air atas
j. Wadah air bawah
k. Keran
1. Balok meja kayu

Setelah komponen-komponen tersebut dibuat, dilanjutkan dengan kegiatan perakitan sehingga diperole sebuat alat uji tarik serat alam seperti pada Gambar di bawah ini. 
67 Muhammad Arsyad, Jeremiah Ritton, Abdul Rachman, Dewi Rachma Ayu Lestari, Edyson Palembangan. Rancang Bangun Alat Uji Tarik Serat Alam

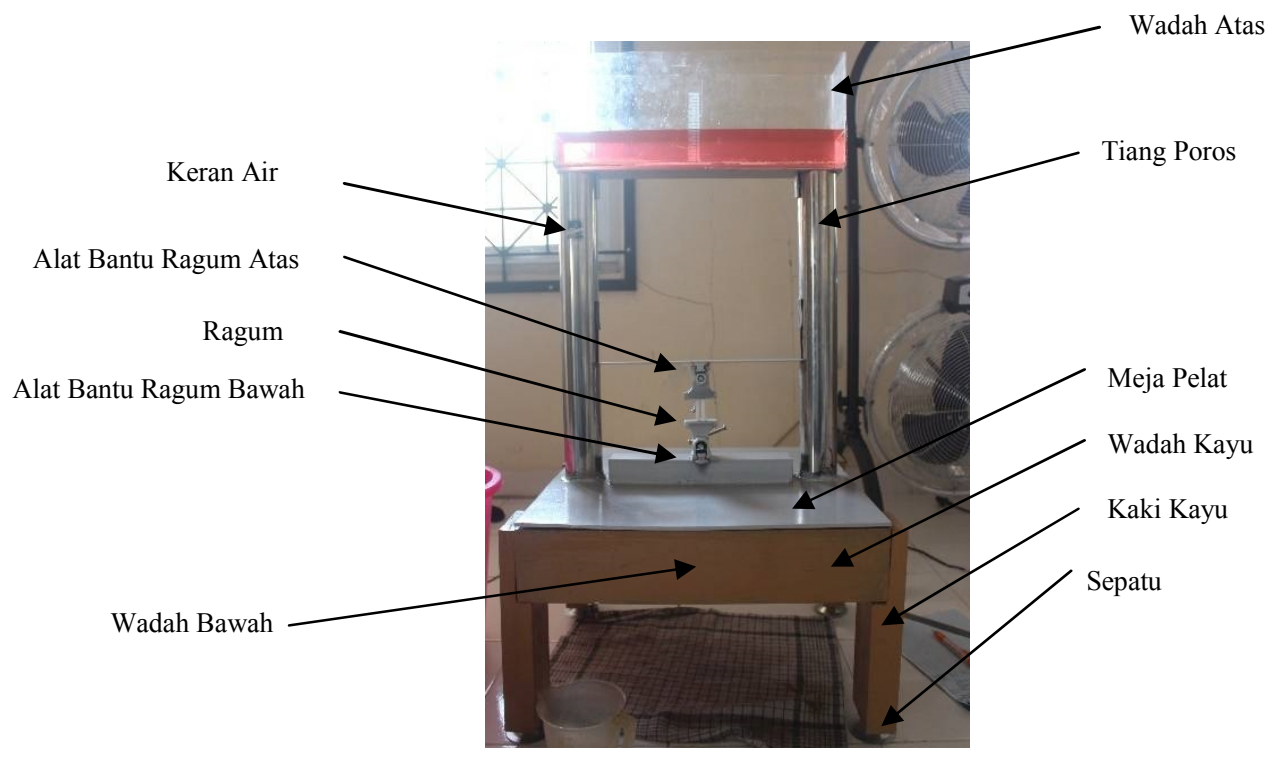

Gambar 1. Alat Uji Tarik Serat Alam

\section{Pengujian}

Pengujian dilakukan dengan mengikuti standar ASTM 3379-02 dengan bentuk spesimen uji seperti diperlihatkan pada Gambar 2 [2].

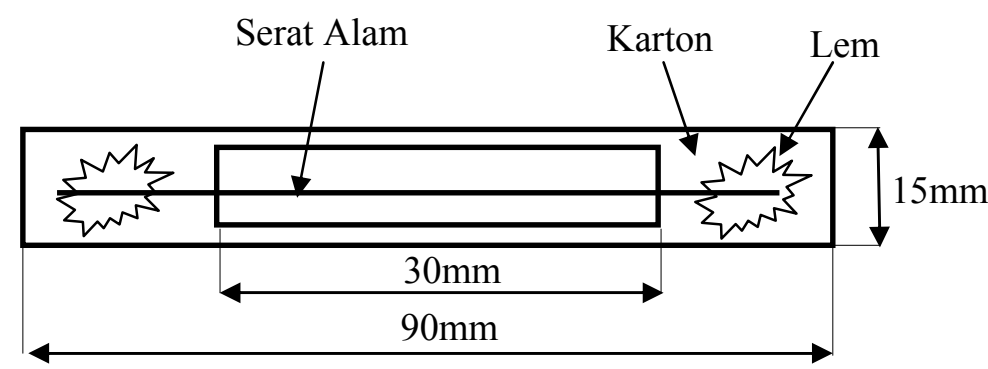

Gambar 2. Spesimen Uji Tarik Serat Alam

Tahapan pengujian terdiri dari:

1. Persiapan

a. Mengukur diameter serat dengan menggunakan mikroskop digital

b. Menyiapkan spesimen uji seperti pada Gambar 2.

c. Menyiapkan air "berwarna"

d. Menyipkan gunting

e. Menyiapkan timbangan digital.

2. Pelaksanaan

a. Meletakkan alat uji pada kondisi datar dan rata ke empat kakinya

b. Menutup keran saluran air

c. Memasukkan air berwarna ke dalam wadah bagian atas

d. Memasang spesimen uji pada ragum, kemudian dijepit/dikencangkan ragumnya

e. Menggunting bagian tengah karton spesimen uji

f. Membuka keran air dengan pembukaan/kecepatan air konstan.

g. Memperhatikan serat hingga putus 
h. Saat serat putus, keran air segera ditutup

i. Mengambil air dari wadah bawah kemudian ditimbang untuk mengetahui massanya.

j. Mencatat dalam tabel beban yang menyebabkan serat putus yaitu massa air dikali dengan percepatan gravitasi.

k. Langkah (a) hingga (j) diulangi untuk pengujian berikutnya.

\section{HASIL DAN PEMBAHASAN}

Hasil yang diperoleh dari kegiatan ini yaitu sebuah alat uji tarik serat alam yang menggunakan air sebagai sebagai beban, dimana massa air sebagai penyebab putusnya serat. Setelah dilakukan pengujian alat uji tarik serat alam tersebut diperoleh massa air yang menyebabkan serat sabut kelapa putus sebagaimana diperlihatkan pada Tabel 1 .

Tabel 1.Data-data Serat Sabut Kelapa

\begin{tabular}{|l|c|c|c|c|c|c|}
\hline \multirow{2}{*}{ No } & $\mathrm{D}$ & $\mathrm{L}_{\mathrm{o}}$ & $\mathrm{L}_{1}$ & $\Delta \mathrm{L}$ & $\mathrm{t}$ & $\mathrm{M}$ \\
\cline { 2 - 7 } & $\mathrm{mm}$ & $\mathrm{Mm}$ & $\mathrm{mm}$ & $\mathrm{mm}$ & $\mathrm{s}$ & $\mathrm{Gr}$ \\
\hline 1 & 0,30 & 30 & 47 & 17 & 270 & 892,7 \\
\hline 2 & 0,20 & 30 & 43 & 13 & 245 & 752,3 \\
\hline 3 & 0,23 & 30 & 40 & 10 & 317 & 1124,1 \\
\hline 4 & 0,21 & 30 & 44 & 14 & 98 & 269,9 \\
\hline
\end{tabular}

$\mathrm{D}=$ Diameter $; \mathrm{L}_{\mathrm{o}}=$ Panjang awal; $\mathrm{L}_{1}=$ Panjang akhir; $\mathrm{t}=$ waktu; $\mathrm{m}=$ massa air

Kekuatan tarik diperoleh dengan menggunakan persamaan berikut [2]:

$\sigma=\frac{F}{A}=\frac{m \cdot g}{\frac{\pi}{4} D^{2}}$

Dimana: $\quad \sigma=$ Kekuatan tarik $\left(\mathrm{N} / \mathrm{mm}^{2}\right)$

$\mathrm{F}=$ Gaya $(\mathrm{N})$

$\mathrm{A}=$ Luas penampang $\left(\mathrm{mm}^{2}\right)$

$\mathrm{m}=$ massa air $(\mathrm{kg})$

$\mathrm{g}=$ percepatan gravitas $\left(9,8 \mathrm{~m} / \mathrm{s}^{2}\right)$

$\mathrm{D}=$ Diameter serat sabut kelapa $(\mathrm{mm})$

Tabel 2. Hasil Uji Tarik Serat Sabut Kelapa

\begin{tabular}{|c|c|c|cc|}
\hline \multirow{2}{*}{ No. } & \multicolumn{3}{|c|}{ Kekuatan Tarik $\left(\mathrm{N} / \mathrm{mm}^{2}\right)$} \\
\cline { 2 - 5 } & Alat Uji Tarik Serat Yang Dibuat & Alat Uji Tarik UNM & \multicolumn{2}{|c|}{ Literatur } \\
\hline 1. & 153,9 & 205,33 & 192,3 & {$[4]$} \\
\hline 2. & 299,0 & 177,14 & 225 & {$[5]$} \\
\hline 3. & 371,5 & 220,78 & 220 & {$[6]$} \\
\hline 4. & 304,0 & 142,43 & 500 & {$[7]$} \\
\hline Rerata & 282,35 & 186,42 & 284,08 \\
\hline
\end{tabular}

Berdasarkan persamaan $1 \mathrm{di}$ atas diperoleh nilai kekuatan tarfik sebagaimana pada Tabel 2 di atas. Untuk mengetahui bahwa alat uji tarik yang dibuat ini bisa digunakan atau memenuhi standar, maka hasil ujinyanya dibandingan dengan salah satu alat uji tarik serat yang ada di Universitas Negeri Makassar (UNM) dan literatur, sebagaimana diperlihatkan pada Tabel 1 di atas. Kekuatan tarik ratarata serat sabut kelapa berdasarkan hasil uji alat yang dibuat diperoleh $282,1 \mathrm{~N} / \mathrm{mm}^{2}$, alat uji tarik UNM diperoleh $186,42 \mathrm{~N} / \mathrm{mm}^{2}$, dan berdasarkan literatur $284,3 \mathrm{~N} / \mathrm{mm}^{2}$. Nilai kekuatan tarik hasil alat yang dibuat terletak antara alat uji tarik UNM dengan Literatur. Hal ini menunjukkan bahwa alat uji tarik yang dibuat memenuhi standar dan bisa digunakan untuk mengetahui kekuatan tarik serat alam.

\section{KESIMPULAN}

Berdasarkan dengan uraian yang dikemukakan sebelumnya maka disimpulkan bahwa alat uji tarik serat alam yang dibuat dapat digunakan untuk mengetahui kekuatan tarik serat alam seperti serat sabut 
69 Muhammad Arsyad, Jeremiah Ritton, Abdul Rachman, Dewi Rachma Ayu Lestari, Edyson Palembangan. Rancang Bangun Alat Uji Tarik Serat Alam

kelapa.

\section{UCAPAN TERIMA KASIH}

Ucapan terima kasih kami sampaikan kepada Pimpinan Politeknik Negeri Ujung Pandang atas bantuan yang diberikan yaitu penggunaan mesin-mesin produksi di Bengkel Mekanik.

\section{DAFTAR PUSTAKA}

[1] Arsyad M, Wahyuni N. "Analisis Pengaruh Lama Perendaman Serat Sabut Kelapa Dalam Larutan $\mathrm{NaOH}$ Terhadap Perubahan Diameter Serat Sabut Kelapa”. Jurnal Sinergi. 13(2):101-110. Oktober 2015

[2] Arsyad, M., Suyuti, M.A., Hidayat, M.F., Pajjarai, A.S. "Pengaruh Variasi Arah Susunan Serat Sabut Kelapa terhadap Sifat Mekanik Komposit Serat Sabut Kelapa". Jurnal Sinergi. 12(2):101-113. Oktober 2014

[3] Sufiandi, Sandi. "Perancangan dan Pengembangan Alat Uji Tarik/Tekan Portabel dengan Data Akusisi". VI (1): 17-18. 2016

[4] Khan, G.M.A., Alam, M.S. "Thermal Characterization of Chemically Treated Coconut Husk Fibre". J.Indian Journal of FIbre \& Textile Research 37: 20-26. 2012.

[5] Jaferjee, Brother. "Composite Applications using Coir Fibers in Sri Lanka". Delft University of Technology, Netherlands. 2003.

[6] Brahmakumar, M., Pavithran, C., and Pillai, R.M. "Coconut Fibre Reinforced Polyethylene Composites : Effect of Natural Waxy Surface Layer of The Fibre/Matrix Interfacial Bonding and Strength of Composites". J. Composites Science and Technology 65: 563-569. 2005.

[7] Li, Xue., Tabil, L.G., Panigrahi, S. "Chemical Treatment of Natural Fiber for Use in Natural Fiber Reinforced Composite: A Review”. J.Polym Environ 15:25-33. 2007. 